\title{
Non-equilibrium solidification of the molten metal droplets impacting on a solid surface
}

\author{
A.I. Fedorchenko ${ }^{1}$, An-Bang Wang* \\ Institute of Applied Mechanics, National Taiwan University, No. 1, Roosevelt Road, Section 4, Taipei 106, Taiwan, ROC
}

Received 16 June 2006; received in revised form 27 October 2006

Available online 13 March 2007

\begin{abstract}
A measuring method for the kinetic coefficient and activation energy of molten metals has been developed. This method is based on a splat thickness measurement of a molten metal droplet deposited on a polished metal substrate. An analytical solution of a non-equilibrium crystallization of a molten metal droplet impacting on a solid substrate relates the thickness of the splat to the kinetic coefficient. The dimensionless number showing the departure of the equilibrium phase transition from the non-equilibrium transition follows from the theory. The predicted values of the kinetic coefficient and activation energy agree well with the existing literature data.
\end{abstract}

(C) 2007 Elsevier Ltd. All rights reserved.

Keywords: Non-equilibrium solidification; Kinetic coefficient; Activation energy; Molten metal; Drop impact

\section{Introduction}

Industrial molten droplet-based applications, such as, thermal spray deposition and solder jet printing, are characterized by the wide gamut of processed materials from fusible metals to refractory oxides and very wide range of the droplet sizes $(5-150 \mu \mathrm{m})$ and impact velocities (1$100 \mathrm{~m} / \mathrm{s}$ ). This in turn results in a wide range of cooling rates from $10^{3}$ up to $10^{8} \mathrm{~K} / \mathrm{s}$ and, correspondingly, a rich diversity of the phase transition scenarios from equilibrium solidification to spontaneous crystallization and metallic glasses formation. Most theoretical studies [1-3] about molten droplet impact on cold substrates under conditions similar to thermal spray deposition have been conducted based on a model of equilibrium solidification. It is worthy of note here that at high rates of cooling molten droplets

\footnotetext{
* Corresponding author. Tel.: +88623356 5651; fax: +8862 33665649. E-mail address: abwang@mems.iam.ntu.edu.tw (A.-B. Wang).

${ }^{1}$ Permanent address: S.S. Kutateladze Institute of Thermophysics, Siberian Branch, Russian Academy of Sciences, 1 Acad. Lavrentyev Ave., 630090 Novosibirsk, Russia.
}

can solidify at considerable undercooling which can attain $100-300 \mathrm{~K}$. In this case, this model of equilibrium crystallization fails to describe properly the dynamics of phase transition and more complicated models, such as the non-equilibrium crystallization [4-6] or nucleation-controlled solidification [7-11] have to be used. At very high cooling rates and in thin molten metal layers transition melt - metallic glasses becomes possible. As shown in $[12,13]$, the critical layer thickness at which the molten metal becomes amorphous is equal to $0.015 \mu \mathrm{m}$ for molten $\mathrm{Al}$ on $\mathrm{Cu}$ substrate and $0.03 \mu \mathrm{m}$ for molten $\mathrm{Ni}$ on $\mathrm{Cu}$ substrate. Thus, at solidification of relatively thick layers, the conditions of equilibrium crystallization described by the Stefan model may be realized. As the thickness of a layer decreases, mechanisms of equilibrium and non-equilibrium solidification begin to compete. Here, however, the following fact should to be noted. The degree of departure of a solidification process (due to undercooling at the front of crystallization) from the equilibrium one depends not only on the thickness of the cooled layer, but also on external conditions, the kinetic and thermophysical properties of the melt and substrate. In [6] it has been shown that for molten metal droplets impacting on a substrate with 


\begin{tabular}{|c|c|c|c|}
\hline \multicolumn{4}{|c|}{ Nomenclature } \\
\hline$a$ & thermal diffusivity $\left(\mathrm{m}^{2} \mathrm{~s}^{-1}\right)$ and radius of a & $T_{\mathrm{m}}$ & melting temperature $(\mathrm{K})$ \\
\hline & spherical crystal (m) & $\Delta T$ & undercooling of the melt, $T_{\mathrm{m}}-T$ \\
\hline$a_{\mathrm{c}}$ & radius of a critical nucleus $(\mathrm{m})$ & $u$ & $z$-component of the velocity of fluid $\left(\mathrm{m} \mathrm{s}^{-1}\right)$ \\
\hline$c$ & specific heat $\left(\mathrm{J} \mathrm{kg}^{-1} \mathrm{~K}^{-1}\right)$ & $v$ & velocity of the front of phase transition $\left(\mathrm{m} \mathrm{s}^{-1}\right)$ \\
\hline$d_{\mathrm{a}}$ & diameter of the atom $(\mathrm{m})$ & $U$ & drop impact velocity $\left(\mathrm{m} \mathrm{s}^{-1}\right)$ \\
\hline$d$ & diameter of the droplet $(\mathrm{m})$ & $W$ & dimensionless energy of activation, $W=E / k T_{\mathrm{m}}$ \\
\hline$D_{\mathrm{L}}$ & coefficient of diffusion $\left(\mathrm{m}^{-2} \mathrm{~s}^{-1}\right)$ & $z$ & axial coordinate $(\mathrm{m})$ \\
\hline$D_{0}$ & $\begin{array}{l}\text { pre-exponential factor }\left(\mathrm{m}^{-2} \mathrm{~s}^{-1}\right), \quad D_{0}=d_{\mathrm{a}}^{2} \\
k T_{\mathrm{m}} / h\end{array}$ & $z_{\mathrm{a}}$ & $\begin{array}{l}\text { instantaneous coordinate of the droplet apex } \\
(\mathrm{m})\end{array}$ \\
\hline Fo & Fourier number, $F_{O}=a_{\mathrm{d}}^{(\mathrm{s})} t / d^{2}$ & $Z$ & dimensionless axial coordinate \\
\hline $\mathrm{Fo}^{*}$ & $\begin{array}{l}\text { dimensionless time of the droplet complete } \\
\text { solidification }\end{array}$ & \multicolumn{2}{|c|}{ Greek symbols } \\
\hline$E$ & energy of activation $\left(\mathrm{J}_{\text {atom }}{ }^{-1}\right)$ & $\alpha$ & coefficient $\left(s^{-1}\right), U /(2 d)$ \\
\hline$h_{\mathrm{p}}$ & Planck constant $(\mathrm{J} \mathrm{s}), 6.6256 \times 10^{-34}$ & $\beta$ & heat transfer coefficient $\left(\mathrm{W} \mathrm{m}^{-2} \mathrm{~K}^{-1}\right)$ \\
\hline$h$ & height of the splat (m) & $\gamma$ & root of transcendental equation \\
\hline$H$ & dimensionless height of the splat, $H=h / d$ & $\eta$ & self-similar variable, $\eta=z(2 \alpha / a)^{1 / 2}$ \\
\hline$k$ & Boltzmann constant $\left(\mathrm{J} \mathrm{K}^{-1}\right), 1.3806 \times 10^{-23}$ & $\lambda$ & thermal conductivity $\left(\mathrm{W} \mathrm{m}^{1} \mathrm{~K}^{-1}\right.$ ) \\
\hline$K$ & kinetic coefficient $\left(\mathrm{m} \mathrm{s}^{-1} \mathrm{~K}^{-1}\right) \sqrt{\left.\left.\gamma^{(\mathrm{s})}\right)^{(\mathrm{s})}\right)^{(\mathrm{s})}}$ & $\theta$ & dimensionless temperature \\
\hline$K_{\varepsilon}$ & relative thermal activity, $K_{\varepsilon}=\sqrt{\frac{\lambda_{\mathrm{d}}^{\mathrm{s}} c_{\mathrm{d}}^{(\mathrm{s}} \rho_{\mathrm{d}}^{(\mathrm{s})}}{\lambda_{\mathrm{s}} c_{\mathrm{s}} \rho_{\mathrm{s}}}}$ & $\rho$ & density $\left(\mathrm{kg} \mathrm{m}^{-3}\right)$ \\
\hline$K u$ & Kutateladze number, $L /\left(c_{\mathrm{d}}^{(\mathrm{s})} T_{\mathrm{m}}\right)$ & $\tau$ & dimensionless time, $\tau=2 \alpha t$ \\
\hline$L$ & latent heat of melting (solidification) $\left(\mathrm{J} \mathrm{kg}^{-1}\right)$ & & instantaneous coordinate of the front of phase \\
\hline$L_{\mathrm{a}}$ & $\begin{array}{l}\text { latent heat of melting per one atom (molecule) } \\
\left(\mathrm{J}_{\text {atom }}^{-1}\right)\end{array}$ & $\Sigma$ & dimensionless coordinate of the front of phase \\
\hline$L_{\mathrm{V}}$ & $\begin{array}{l}\text { volumetric latent heat of solidification }\left(\mathrm{J} \mathrm{m}^{-3}\right) \text {, } \\
L_{\mathrm{V}}=\rho L\end{array}$ & $\Omega$ & $\begin{array}{l}\text { transition } \\
\text { criterion of the phase transition, } \beta /\left(L_{\mathrm{V}} K\right)\end{array}$ \\
\hline & $\begin{array}{l}\text { effective dimensionless heat of melting, } \\
L_{\mathrm{eff}}=K u+\lambda^{(1, \mathrm{~s})} N u R\end{array}$ & \multicolumn{2}{|c|}{ Subscripts } \\
\hline$n$ & $\begin{array}{l}\text { number of atoms (molecules) per unit volume } \\
\left(\mathrm{m}^{-1}\right)\end{array}$ & $\begin{array}{l}\mathrm{d} \\
\mathrm{eq}\end{array}$ & $\begin{array}{l}\text { refers to droplet } \\
\text { refers to equilibrium solidification }\end{array}$ \\
\hline$N u$ & Nusselt number, $N u=\beta d / \lambda_{d}^{(1)}$ & $\mathrm{n}$ & refers to non-equilibrium solidification \\
\hline$P e$ & Peclet number, $P e=U d / a_{\mathrm{d}}^{(1)}$ & f & refers to the front of phase transition \\
\hline$q$ & heat flux $\left(\mathrm{W} \mathrm{m}^{-2}\right)$ & $\mathrm{s}$ & refers to substrate \\
\hline & radial coordinate $(\mathrm{m})$ & \multicolumn{2}{|c|}{ Superscripts } \\
\hline$R$ & $\begin{array}{l}\text { ratio of diffusive and kinetic velocities, } \\
R=a_{\mathrm{d}}^{(\mathrm{s})} /\left(d K T_{\mathrm{m}}\right)\end{array}$ & & refers to liquid phase \\
\hline$t$ & time $(\mathrm{s})$ & $\mathrm{s}$ & refers to solid phase \\
\hline$t^{*}$ & time of the droplet complete solidification & & \\
\hline
\end{tabular}

conditions similar to thermal spraying, solidification can follow both equilibrium and non-equilibrium mechanisms. Therefore, it is advisable to determine the criterion for predicting a priory the scenario of the phase transition. Another important issue is the evaluation of the kinetic coefficient $K$ representing the proportionality constant between crystal growth velocity and undercooling. Usually, the value of the kinetic coefficient is estimated from thermophysical data, but these estimates are prone to the gross uncertainty. For example, Clyne [7] gives $K=0.012$ for molten nickel whereas Regel and Glazov [14] and Zhang et al. [5] give $K=0.005$ and $K=0.85$, respectively. Therefore, another goal of this study is to develop a theoretical model which can be used as the basis for an experimental measurement of the activation energy and kinetic coefficient of molten metals.

\section{Statement of the problem}

\subsection{Criterion of the phase transition scenario}

It is well known that the principal difference between equilibrium (Stefan problem) and non-equilibrium crystallizations is the presence of undercooling $\Delta T_{\mathrm{f}}=T_{\mathrm{m}}-T_{\mathrm{f}}$ at an interface liquid/solid. In this case the interface velocity for liquid metals is determined as

$v=K \Delta T_{\mathrm{f}}$, 
where $K$ is the kinetic coefficient which can be considered as a constant at small values of $\Delta T_{\mathrm{f}}$.

At the solid-liquid interface, where the change of state occurs, an energy balance is maintained:

$\rho L u=[q]_{\mathrm{f}}$,

where $[q]_{\mathrm{f}}$ is the jump of heat fluxes at the front of phase transition.

In the case of equilibrium phase transition $\Delta T_{\mathrm{f}}=0$, therefore Eq. (1) degenerates and only the equation of energy balance (2) controls the dynamics of phase transition. However, we can formally consider an equilibrium phase transition as a non-equilibrium one with $K \rightarrow \infty$ and $\Delta T_{\mathrm{f}} \rightarrow 0$, so that the following limit yields a finite equilibrium velocity of the front:

$v_{\mathrm{eq}}=\lim _{\substack{\Delta T \rightarrow 0 \\ K \rightarrow \infty}} K \Delta T_{\mathrm{f}}$

Furthermore, the rate of the undercooling $\Delta T_{\mathrm{f}}$ diminution in the non-equilibrium case depends on the latent heat of solidification $L$, the convective heat transfer coefficient $\beta$ at the front of phase transition, and the kinetic coefficient $K$. If, instead of $L$, one chooses the volumetric latent heat $L_{\mathrm{V}}=\rho L$, then there exists only one dimensionless combination $\Omega$ of these three parameters:

$\Omega=\beta /\left(L_{\mathrm{V}} K\right)$.

From Eqs. (3) and (4) an important conclusion can be drawn that the condition $\Omega \ll 1$ corresponds to the case of equilibrium solidification. Consequently, $\Omega$ may serve as a criterion predicting $a$ priory the scenario of the phase transition (equilibrium or non-equilibrium).

\subsection{Model of the non-equilibrium droplet crystallization}

Let us consider a molten metal droplet of diameter $d$ and velocity $U$ at the melting temperature $T_{\mathrm{m}}$ impinging perpendicularly on a cold, flat, and rigid surface. Also assume that at the melt/substrate interface at $z=0$ ideal contact is realized and the thermophysical properties of the solid and liquid phases are constant. At the instant $t=0$, when droplet comes into contact with surface, the front of the phase transition $\zeta(t, r)$ starts to move in the positive $z$-axis direction with the speed $\mathrm{d} \zeta(t, r) / \mathrm{d} t=f(\Delta T)$ toward to the apex $z_{\mathrm{a}}(t)$ of the spreading droplet, thereby the delay time of nucleation is set to zero. As shown later, these assumptions correspond to experimental conditions. For metal melts $f(\Delta T)=K \Delta T$, hence an equation of interface motion takes the form

$\mathrm{d} \zeta(t, r) / \mathrm{d} t=K \Delta T$,

where $K$ is the kinetic coefficient which can be considered constant at small overcooling. Then the time $t^{*}$ required for the droplet complete crystallization can be found from this equation

$\zeta\left(t^{*}, 0\right)=\zeta_{0}\left(t^{*}\right)=z_{\mathrm{a}}\left(t^{*}\right)$.
The final shape of the splat is a flat disk with the constant thickness over the splat radius; therefore it is enough to determine the splat thickness only in one point. The simplest way is to formulate the problem for the drop's axis of symmetry $(r=0)$ as was done in [2] for the case of equilibrium droplet solidification. Then, the governing equations are described as follows:

$\partial_{t} T_{\mathrm{s}}=a_{\mathrm{s}} \partial_{z z} T_{\mathrm{s}} \quad$ at $-\infty<z<0$,

$\partial_{t} T_{\mathrm{d}}^{(\mathrm{s})}=a_{\mathrm{d}}^{(\mathrm{s})} \partial_{z z} T_{\mathrm{d}}^{(\mathrm{s})} \quad$ at $0<z<\zeta_{0}(t)$.

At the solid phase/substrate $z=0$ the fourth-kind boundary conditions are maintained:

$T_{\mathrm{s}}(t, 0)=T_{\mathrm{d}}^{(\mathrm{s})}(t, 0), \quad \lambda_{\mathrm{s}}\left(\partial_{z} T_{\mathrm{s}}\right)_{z=0}=\lambda_{\mathrm{d}}^{(\mathrm{s})}\left(\partial_{z} T_{\mathrm{d}}^{(\mathrm{s})}\right)_{z=0}$.

At the solid-liquid front of phase transition $z=\zeta_{0}(t)$ the energy balance can be written as follows:

$\lambda_{\mathrm{d}}^{(\mathrm{s})}\left(\partial_{z} T_{\mathrm{d}}^{(\mathrm{s})}\right)_{z=\varsigma_{0}(t)}=\rho_{\mathrm{d}}^{(\mathrm{s})} L \frac{\mathrm{d} \zeta_{0}(t)}{\mathrm{d} t}+\beta_{\mathrm{m}}\left(T_{\mathrm{m}}-T_{\mathrm{f}}\right)$,

where $T_{\mathrm{f}}$ is the temperature at the front of crystallization, $\beta_{\mathrm{m}}$ is the mean heat transfer coefficient.

Including the boundary condition

$T_{\mathrm{s}}(t,-\infty)=T_{\mathrm{s} 0}$

closes the statement of the problem.

Introducing the following dimensionless variables $Z=z / d, F o=a_{\mathrm{d}}^{(\mathrm{s})} t / d^{2}, \theta=T / T_{\mathrm{m}}$, the governing equations (5), (7)-(11) can be rewritten as follows:

$\frac{\partial \theta_{\mathrm{s}}}{\partial F_{O}}=a_{\mathrm{s}, \mathrm{d}} \frac{\partial^{2} \theta_{\mathrm{s}}}{\partial Z^{2}}$,

$\frac{\partial \theta_{\mathrm{d}}}{\partial F_{O}}=\frac{\partial^{2} \theta_{\mathrm{d}}}{\partial Z^{2}}$,

$\theta_{\mathrm{s}}(0, F o)=\theta_{\mathrm{d}}(0, F o), \quad \lambda_{\mathrm{s}, \mathrm{d}}\left(\partial \theta_{\mathrm{s}} / \partial Z\right)_{Z=0}=\left(\partial \theta_{\mathrm{d}} / \partial Z\right)_{Z=0}$,

$\theta_{\mathrm{f}}=1-R \frac{\mathrm{d} \Sigma}{\mathrm{d} F o}$,

$\left.\frac{\partial \theta_{\mathrm{d}}}{\partial Z}\right|_{Z=\Sigma}=L_{\mathrm{eff}} \frac{\mathrm{d} \Sigma}{\mathrm{d} F o}$.

Here $R=a_{\mathrm{d}}^{(\mathrm{s})} /\left(d K T_{\mathrm{m}}\right)$ is the diffusive and kinetic velocities ratio, $K u=L /\left(c_{\mathrm{d}}^{(\mathrm{s})} T_{\mathrm{m}}\right)$ is the Kutateladze number, $N u=\beta_{\mathrm{m}} d / \lambda_{\mathrm{d}}^{(1)}$ is the Nusselt number, $L_{\mathrm{eff}}=K u+\lambda_{\mathrm{d}}^{(1, \mathrm{~s})} N u R$ is the effective latent heat, $\lambda_{\mathrm{s}, \mathrm{d}}=\lambda_{\mathrm{s}} / \lambda_{\mathrm{d}}^{(\mathrm{s})}, a_{\mathrm{s}, \mathrm{d}}=a_{\mathrm{s}} / a_{\mathrm{d}}^{(\mathrm{s})}$, $\lambda_{\mathrm{d}}^{(1, \mathrm{~s})}=\lambda_{\mathrm{d}}^{(1)} / \lambda_{\mathrm{d}}^{(\mathrm{s})}, \Sigma=\zeta_{0} / d$.

An analytical solution of Eqs. (11)-(16) can be found by the method given in Lyubov [15]. Omitting intermediate cumbersome mathematics, the instantaneous dimensionless coordinate of the front of phase transition $\Sigma$ is determined by the expression

$\Sigma=2 \gamma F^{1 / 2}$,

where the constant $\gamma$ is the root of the following characteristic equation

$\frac{1-\theta_{\mathrm{s} 0}}{K u+\lambda_{\mathrm{d}}^{(1, \mathrm{~s})} N u R}=\sqrt{\pi} \gamma\left[K_{\varepsilon}+\operatorname{erf}(\gamma)\right] \mathrm{e}^{\gamma^{2}}$. 
Here $K_{\varepsilon}=\sqrt{\frac{\lambda_{\mathrm{d}}^{(\mathrm{s})} c_{\mathrm{d}}^{(\mathrm{s})} \rho_{\mathrm{d}}^{(\mathrm{s})}}{\lambda_{\mathrm{s}} c_{\mathrm{s}} \rho_{\mathrm{s}}}}$ is the relative heat activity, $\theta_{\mathrm{s} 0}=T_{\mathrm{s} 0} / T_{\mathrm{m}}$.

From Eq. (18) it follows that the above-introduced dimensionless number $\Omega$ does characterize the impact of kinetics itself on the process of crystallization

$\Omega=\lambda_{\mathrm{d}}^{(1, \mathrm{~s})} N u R / K u=\beta_{\mathrm{m}} /\left(L_{\mathrm{V}} K\right)$,

where $L_{\mathrm{V}}=\rho_{\mathrm{d}}^{(\mathrm{s})} L$ is the volumetric latent heat.

Accounting for Eq. (19), Eq. (18) becomes

$\frac{1-\theta_{\mathrm{s} 0}}{K u(1+\Omega)}=\sqrt{\pi} \gamma\left[K_{\varepsilon}+\operatorname{erf}(\gamma)\right] \mathrm{e}^{\gamma^{2}}$.

According to condition (3) $K \rightarrow \infty$ at equilibrium crystallization, correspondingly, $\Omega$ becomes infinitesimally small, so that, it can be neglected in comparison to unity in Eq. (20). In this case, the dynamics of crystallization is determined solely by the criterion of the equilibrium crystallization $K u$. At finite $\Omega$-values, the phase transition depends essentially on the kinetics.

The height of the splat can be determined from the model. The apex of the spreading droplet keeps the initial droplet impact velocity $U$ during the considered time interval [16]. Then, by virtue of Eqs. (6) and (17), the equation determining the time of the droplet complete solidification takes the form

$1-\delta P e F o=2 \gamma F^{1 / 2}$,

where $\delta=a_{\mathrm{d}}^{(1, \mathrm{~s})}, P e=U d / a_{\mathrm{d}}^{(1)}$ is the Peclet number, $\gamma$ is the root of Eq. (20), $a_{\mathrm{d}}^{(1, \mathrm{~s})}=a_{\mathrm{d}}^{(1)} / a_{\mathrm{d}}^{(\mathrm{s})}$.

The root $\mathrm{Fo}^{*}$ of Eq. (21) is given by the following expression

$F^{*}=\frac{2 \gamma^{2}+\delta P e-2 \gamma \sqrt{\gamma^{2}+\delta P e}}{\delta^{2} P e^{2}}$

Substituting Eq. (22) into Eq. (21) yields the dimensionless height of the splat $H=h / d$

$H=1-\delta P e F^{*}=2 \gamma F^{* 1 / 2}$.

In preparation for using the obtained Eqs. (20)-(23), one needs to evaluate the heat transfer coefficient $\beta_{\mathrm{m}}$ and kinetic coefficient $K$.

\section{Convective heat transfer in the vicinity of a stagnation point}

To determine the heat transfer coefficient, now consider the axisymmetric non-isothermic incompressible fluid flow in the vicinity of a stagnation point. Since for metal melts the Prandtl number is small $\left(\operatorname{Pr}=10^{-2}-10^{-3}\right)$, the normal component of the fluid velocity $u$ could be taken from the solution of inviscid stagnation flow impinging on a solid surface:

$u=-2 \alpha z$.

According to [2], the coefficient $\alpha$ is

$\alpha=U /(2 d)$.
Then, the governing equation and boundary conditions along the central line $r=0$ of the flow are described as follows:

$\partial_{t} T-2 \alpha z \partial_{z} T=a \partial_{z z} T$

$T(t, \infty)=T(0, z)=T_{1}, \quad T(t, 0)=T_{2}=$ constant.

Introducing the following dimensionless variables $\theta=$ $\left(T-T_{1}\right) /\left(T_{2}-T_{1}\right), \quad \eta=z(2 \alpha / a)^{1 / 2}, \tau=2 \alpha t, \quad$ governing equations (26) and (27) can be written as

$\partial_{\tau} \theta-\eta \partial_{\eta \eta} \theta=\partial_{\eta \eta} \theta$

$\theta(\tau, \infty)=\theta(0, \eta)=0, \quad \theta(\tau, 0)=1$.

The problem (28) and (29) has the self-similar solution. Introducing a new variable $\xi=\eta / f(\tau)$ with unknown function $f(\tau)$, Eq. (28) takes the form

$\frac{\mathrm{d}^{2} \theta}{\mathrm{d} \xi^{2}}+\xi\left(f f^{\prime}+f^{2}\right) \frac{\mathrm{d} \theta}{\mathrm{d} \xi}=0$,

where $f^{\prime} \equiv \mathrm{d} f / \mathrm{d} \tau$.

Equating the expression in brackets to unity yields the explicit form of the function $f$ :

$f(\tau)=[1-\exp (-2 \tau)]^{1 / 2}$.

The solution of the equation

$\frac{\mathrm{d}^{2} \theta}{\mathrm{d} \xi^{2}}+\xi \frac{\mathrm{d} \theta}{\mathrm{d} \xi}=0$

satisfying the boundary conditions $\theta(\infty)=0$ and $\theta(0)=1$, reads

$\theta(\xi)=1-\sqrt{\frac{2}{\pi}} \int_{0}^{\xi} \exp \left(-\frac{x^{2}}{2}\right) \mathrm{d} x$

To find the instantaneous value of the Nusselt number $N u=\beta d / \lambda_{\mathrm{d}}^{(1)}$, it can be rewritten in the following form:

$N u=\frac{q d}{\lambda_{\mathrm{d}}^{(1)}\left(T_{1}-T_{2}\right)}=\left.\frac{d}{T_{1}-T_{2}} \frac{\partial T}{\partial z}\right|_{z=0}$,

where $q=\lambda_{\mathrm{d}}^{(1)}(\partial T / \partial z)_{z=0}$ is the magnitude of heat flux at the interface melt/substrate.

Calculating the derivative $(\partial T / \partial z)$ at $z=0$ with accounting for (31) and (33) yields

$N u=\sqrt{\frac{4 \alpha}{\pi a}} d[1-\exp (-2 \tau)]^{-1 / 2}$.

Furthermore, accounting for (25), Eq. (35) reads

$N u=\sqrt{\frac{2 P e}{\pi}}[1-\exp (-2 \tau)]^{-1 / 2}$.

Averaging (36) over the temporal scale $d / U$ of the droplet deformation that corresponds to the dimensionless time $\tau=1$, finally yields

$N u_{\mathrm{m}}=(5.5 P e / \pi)^{1 / 2}$,

$\beta_{\mathrm{m}}=(5.5 P e / \pi)^{1 / 2} \lambda_{\mathrm{d}}^{(1)} / d$. 


\section{Results and discussion}

The classical treatment of crystal continuous growth leads to an expression for the velocity of spherical crystal growth [17]

$\frac{\mathrm{d} a}{\mathrm{~d} t}=\frac{d_{\mathrm{a}}}{n h_{\mathrm{p}}} \frac{L_{\mathrm{V}}}{T_{\mathrm{m}}} \mathrm{e}^{-E / k T} \Delta T\left(1-\frac{a_{\mathrm{c}}}{a}\right)$,

where $d_{\mathrm{a}}$ is the effective diameter of atom (molecule), $a$ is the spherical crystal radius, $E$ is the activation energy, $L_{\mathrm{V}}$ is the volumetric heat of melting, $h_{\mathrm{p}}$ is the Planck constant, $k$ is the Boltzmann constant, $n$ is the number of atoms (molecules) per unit volume, $\Delta T=T_{\mathrm{m}}-T$ is the melt undercooling, $T_{\mathrm{m}}$ is the melting temperature, $a_{\mathrm{c}}$ is the critical nucleus radius.

In case of $a_{\mathrm{c}} \ll a$ and at low $\Delta T\left(\Delta T / T_{\mathrm{m}} \ll 1\right)$, Eq. (39) reads

$v=\mathrm{d} a / \mathrm{d} t=K \Delta T$,

where $K=\frac{d_{\mathrm{a}}}{n h_{\mathrm{p}}} \frac{L_{\mathrm{v}}}{T_{\mathrm{m}}} \exp \left(-E / k T_{\mathrm{m}}\right)$ is the kinetic coefficient.

It is convenient to rewrite the expression for the kinetic coefficient in the following way:

$K=\frac{d_{\mathrm{a}}}{n h_{\mathrm{p}}} \frac{L_{\mathrm{V}}}{T_{\mathrm{m}}} \mathrm{e}^{-W}=\frac{d_{\mathrm{a}}^{2}}{\left(h_{\mathrm{p}} / k T_{\mathrm{m}}\right)} \mathrm{e}^{-W} \frac{L_{\mathrm{a}}}{d_{\mathrm{a}} k T_{\mathrm{m}}^{2}}$,

where $L_{\mathrm{a}}=L_{\mathrm{V}} / n$ is the latent heat of melting per one atom (molecule), $W=E / k T_{\mathrm{m}}$.

Introducing the designations $D_{\mathrm{L}}=D_{0} \mathrm{e}^{-W}$ and $D_{0}=$ $\frac{d_{\mathrm{a}}^{2}}{\left(h_{\mathrm{p}} / k T_{\mathrm{m}}\right)}$, the kinetic coefficient becomes

$K=\frac{D_{\mathrm{L}} L_{\mathrm{a}}}{d_{\mathrm{a}} k T_{\mathrm{m}}^{2}}$.

Thereby the expression (40) for the velocity of crystal growth reduces to the Wilson-Frenkel form

$v=\frac{D_{\mathrm{L}} L_{\mathrm{a}}}{d_{\mathrm{a}} k T_{\mathrm{m}}^{2}} \Delta T$.

The application of the developed model has been performed based on the experimental data $[18,19]$. Separate molten droplets were obtained by spraying a wire in an independent arc plasma jet having a high-temperature, small-size zone. The distance between the nozzle exit and the substrate was chosen so that the droplets fell on a specimen's surface (polished up to $\Delta 14$ class of surface finish) in a molten state at melting temperature. The temperature of the heated substrate was controlled. The velocities of the droplets before collision with substrate were close to $30 \mathrm{~m} / \mathrm{s}$.

Table 1 lists experimental data from $[18,19]$ used in the present study and the dimensionless values of the splat height obtained from both equilibrium [2] $\left(H_{\mathrm{eq}}=h_{\mathrm{eq}} / d\right)$ and non-equilibrium $\left(H_{\mathrm{n}}=h_{\mathrm{n}} / d\right)$ models. As follows from $[11,13,17]$, the effect of nucleation delay can be neglected at droplet impact parameters listed in Table 1.

The thermophysical and kinetic properties of the materials were taken from $[7,14,20,21]$ (Tables 2 and 3). As can be seen from Table 1, the experimental and calculated
Table 1

Experimental conditions and corresponding $\Omega$-values, measured $\left(H_{\exp }\right)$ and calculated from equilibrium $\left(H_{\mathrm{eq}}\right)$ and non-equilibrium $\left(H_{\mathrm{n}}\right)$ models values of the splat height

\begin{tabular}{lllllllll}
\hline $\begin{array}{l}\text { Drop- } \\
\text { substrate }\end{array}$ & $\begin{array}{l}d, \\
\mu \mathrm{m}\end{array}$ & $\begin{array}{l}U_{0}, \\
\mathrm{~m} / \mathrm{s}\end{array}$ & \multicolumn{1}{c}{$\begin{array}{c}T_{\mathrm{p} 0}, \\
\mathrm{~K}\end{array}$} & $\begin{array}{l}T_{\mathrm{s} 0}, \\
\mathrm{~K}\end{array}$ & $H_{\text {exp }}$ & $H_{\mathrm{n}}$ & $H_{\text {eq }}$ & $\Omega$ \\
\hline $\mathrm{Al}-\mathrm{Ag}$ & 180 & 30 & 933 & 673 & 0.068 & 0.068 & 0.086 & 0.18 \\
$\mathrm{Ag}-\mathrm{Ag}$ & 162 & 30 & 1234 & 573 & 0.111 & 0.111 & 0.188 & 0.82 \\
$\mathrm{Cu}-\mathrm{Ag}$ & 120 & 30 & 1356 & 573 & 0.083 & 0.082 & 0.14 & 1.12 \\
$\mathrm{Ni}-\mathrm{Ag}$ & 80 & 30 & 1726 & 673 & 0.063 & 0.064 & 0.118 & 1.16 \\
\hline
\end{tabular}

Table 2

Thermophysical properties of materials for solid and liquid states at melting temperature

\begin{tabular}{|c|c|c|c|c|c|}
\hline $\begin{array}{l}\text { Material of } \\
\text { the droplet }\end{array}$ & $\begin{array}{l}\rho^{(\mathrm{s})} / \rho^{(1)} \\
\left(\mathrm{kg} \mathrm{m}^{-3}\right)\end{array}$ & $\begin{array}{l}c^{(\mathrm{s})} / c^{(1)} \\
\left(\mathrm{J} \mathrm{kg}^{-1} \mathrm{~K}^{-1}\right)\end{array}$ & $\begin{array}{l}\lambda^{(\mathrm{s})} / \lambda^{(1)} \\
\left(\mathrm{W} \mathrm{m}^{-1} \mathrm{~K}^{-1}\right)\end{array}$ & $\begin{array}{l}T_{\mathrm{m}} \\
(\mathrm{K}) \\
\end{array}$ & $\begin{array}{l}L \\
\left(\mathrm{~kJ} \mathrm{~kg}^{-1}\right) \\
\end{array}$ \\
\hline $\mathrm{Al}$ & $\begin{array}{l}2600 / \\
2370\end{array}$ & $890 / 1095$ & $220 / 88$ & 933 & 397 \\
\hline $\mathrm{Ag}$ & $\begin{array}{l}9820 / \\
9320\end{array}$ & $298 / 283$ & $370 / 180$ & 1234 & 105 \\
\hline $\mathrm{Cu}$ & $\begin{array}{l}8930 / \\
8030\end{array}$ & $390 / 500$ & $275 / 180$ & 1356 & 205 \\
\hline $\mathrm{Ni}$ & $\begin{array}{l}8900 / \\
7790\end{array}$ & $667 / 770$ & $77 / 70$ & 1728 & 298 \\
\hline
\end{tabular}

Table 3

The kinetic properties of liquid metals from the literature

\begin{tabular}{llllc}
\hline Melt & $\mathrm{Al}$ & $\mathrm{Ag}$ & $\mathrm{Cu}$ & $\mathrm{Ni}$ \\
\hline$d_{\mathrm{a}}, 10^{-10} \mathrm{~m}$ & 2.67 & 2.68 & 2.3 & 2.33 \\
$D_{0}, 10^{-7} \mathrm{~m}^{2} / \mathrm{s}$ & 2.0 & 0.9 & 0.8 & 1.8 \\
$E, 10^{-20} \mathrm{~J} / \mathrm{atom}$ & 4.15 & 5.13 & 6.6 & 10.9 \\
$L_{\mathrm{a}}, 10^{-20} \mathrm{~J} /$ atom & 1.75 & 1.87 & 2.15 & 2.95 \\
$K, \mathrm{~m} /(\mathrm{s} \mathrm{K})$ & 0.044 & 0.015 & 0.009 & 0.005 \\
$W=E / k T_{\mathrm{m}}$ & 3.222 & 3.011 & 3.525 & 4.611 \\
\hline
\end{tabular}

non-equilibrium values of the dimensionless height practically coincide. The equilibrium values of the height remain relatively close to the experimental ones $(\mathrm{Al}-\mathrm{Ag})$ only for small values of $\Omega(\Omega=0.18)$. At $\Omega=0.82(\mathrm{Ag}-\mathrm{Ag})$ the error increases drastically and the equilibrium model fails to describe the process of droplet solidification.

The excellent agreement of the splat thickness experimental values and predicted ones from non-equilibrium model allows one to suggest a method for the kinetic coefficient and activation energy determination. Assuming the value of $H$ is known from the experiment, one can find successively $\mathrm{Fo}^{*}$ from the first equality (23), $\gamma$ from the second one (23), $\Omega$ from (20), and ultimately $K$ from (19).

Table 4 shows the comparison of predicted values of kinetic coefficient $K_{\text {calc }}$ and dimensionless activation energy $W_{\text {calc }}$ with those from literature. The predicted values of activation energy $W_{\text {calc }}$ agree well with data from Table 3 and have a maximum deviation of $1.8 \%$ for $\mathrm{Ni}$. The nickel has the highest value of the activation energy ( $W=4.611)$ which is in agreement with its inclination for amorphysation $[12,13]$. 
Table 4

Comparison of predicted values of kinetic coefficient and activation energy and those from literature

\begin{tabular}{lllll}
\hline Drop-substrate & $K, \mathrm{~m} \mathrm{~s}^{-1}$ & $K_{\text {calc }}, \mathrm{m} \mathrm{s}^{-1}$ & $W$ & $W_{\text {calc }}$ \\
\hline $\mathrm{Al}-\mathrm{Ag}$ & 0.044 & 0.044 & 3.222 & 3.214 \\
$\mathrm{Ag}-\mathrm{Ag}$ & 0.015 & 0.015 & 3.011 & 3.014 \\
$\mathrm{Cu}-\mathrm{Ag}$ & 0.009 & 0.009 & 3.525 & 3.498 \\
$\mathrm{Ni}-\mathrm{Ag}$ & 0.005 & 0.005 & 4.611 & 4.694 \\
\hline
\end{tabular}

\section{Conclusions}

The criterion $\Omega$ for predicting the scenario of a phase transition for the molten metal droplets impacting on a solid surface has been suggested. At $\Omega \ll 1$, the phase transition proceeds as an equilibrium one. As $\Omega$-value increases, the equilibrium model fails to describe droplet solidification. A model for non-equilibrium crystallization of molten metal droplets impacting on a solid substrate has also been developed. An analytical solution of the model relates the splat thickness to the kinetic coefficient of the molten high-melting metals. This offers a new method for measuring the kinetic coefficient and activation energy of molten metals by means of splat thickness measurement of molten metal droplets deposited on a polished specimen surface.

\section{Acknowledgements}

The authors thank J.N. Ho for editorial corrections. This work was supported by the National Science Council, Taiwan, Republic of China under Grant No. NSC93-2811E-002-037.

\section{References}

[1] J. Madejski, Solidification droplets on a cold surface, Int. Heat Mass Transfer 19 (1976) 1009-1013.

[2] A.I. Fedorchenko, O.P. Solonenko, Dynamics of crystallization process of molten particles at their interaction with surface, in: O.P. Solonenko, A.I. Fedorchenko (Eds.), Plasma Jets in the Development of New Materials Technology, VSP, Utrecht, The Netherlands; Tokyo, Japan, 1990, pp. 283-297.

[3] H. Zhang, Theoretical analysis of spreading and solidification of molten droplet during thermal spray deposition, Int. J. Heat Mass Transfer 42 (1999) 2499-2508.

[4] M. Chung, R.H. Rangel, Parametric study of metal droplet deposition and solidification process including contact resistance and undercooling effects, Int. J. Heat Mass Transfer 44 (2001) 605-618.

[5] H. Zhang, X.Y. Wang, L.L. Zheng, X.Y. Jiang, Studies of splat morphology and rapid solidification during thermal spraying, Int. J. Heat Mass Transfer 44 (2001) 4579-4592.

[6] A.I. Fedorchenko, Phase transition upon solidification from a liquid state, J. Appl. Mech. Tech. Phys. 42 (1) (2001) 97-102.

[7] T.W. Clyne, Numerical treatment of rapid solidification, Metall. Trans. B 15 (1984) 369-381.

[8] W.T. Kim, D.L. Zhang, B. Cantor, Nucleation of solidification in liquid droplets, Metall. Trans. A 22 (1991) 2487-2501.

[9] D.M. Herlach, Non-equilibrium solidification of undercooled metallic melts, Mater. Sci. Eng. R 12 (1994) 179-272.

[10] K.-C. Chang, C.-M. Chen, Revisiting heat transfer analysis for rapid solidification of metal droplets, Int. J. Heat Mass Transfer 44 (2001) $1573-1583$

[11] A.I. Fedorchenko, A.A. Chernov, Simulation of the microstructure of a thin metal layer quenched from a liquid state, Int. J. Heat Mass Transfer 46 (2003) 921-929.

[12] A.P. Baikov, V.A. Ivanchenko, V.I. Motorin, S.L. Musher, A.F. Shestak, The one-component metallic glasses from nickel and molybdenum, Phys. Lett. 113A (1) (1985) 38-40.

[13] A.A. Chernov, A.I. Fedorchenko, A glass transition criterion for metal melts under quenching from the liquid state, Russ. J. Eng. Thermophys. 10 (3) (2000) 201-206.

[14] A.R. Regel, V.M. Glazov, Physical Properties of Electron Melts, Nauka, Moscow, 1980.

[15] B.Ya. Lyubov, Theory of Crystallization in Large Volumes, Nauka, Moscow, 1975 (in Russian).

[16] A.I. Fedorchenko, A.-B. Wang, On some common features of drop impact on liquid surface, Phys. Fluids 16 (5) (2004) 1349-1365.

[17] A.I. Fedorchenko, Hydrodynamical and thermophysical peculiarities of a molten droplet impact on a solid surface, Doctoral (Phys. and Math.) dissertation, Novosibirsk, Inst. Thermophysics, 2000.

[18] V.V. Kudinov, Plasma Coating, Nauka, Moscow, 1977.

[19] V.V. Kudinov, V.M. Ivanov, Plasma Spraying of Refractory Coatings, Masinostroyeniye, Moscow, 1981.

[20] V.E. Zinovyev, Kinetic Properties of Metals at High Temperatures, Metallurgy, Moscow, 1984.

[21] A.R. Ubbelohde, The Molten State of Matter: Melting and Crystal Structure, Wiley, New York, 1978. 